\title{
BIROLI, Flávia. Autonomia e Desigualdades de Gênero: contribuições do feminismo para a crítica democrática
}

Izis Morais Lopes dos Reis

\section{(2) OpenEdition}

1 Journals

Edição electrónica

URL: http://journals.openedition.org/aa/717

DOI: $10.4000 /$ aa. 717

ISSN: 2357-738X

Editora

Programa de Pós-Graduação em Antropologia Social (UnB)

\section{Edição impressa}

Data de publição: 1 junho 2014

Paginação: 249-253

ISSN: 0102-4302

\section{Refêrencia eletrónica}

Izis Morais Lopes dos Reis, «BIROLI, Flávia. Autonomia e Desigualdades de Gênero: contribuições do feminismo para a crítica democrática», Anuário Antropológico [Online], v.39 n. 1 | 2014, posto online no dia 01 outubro 2014, consultado o 27 abril 2021. URL: http://journals.openedition.org/aa/717 ; DOI: https://doi.org/10.4000/aa.717

Este documento foi criado de forma automática no dia 27 abril 2021.

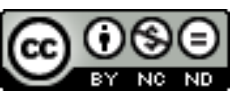

Anuário Antropológico is licensed under a Creative Commons Atribuição-Uso Não-Comercial-Proibição de realização de Obras Derivadas 4.0 International. 


\title{
BIROLI, Flávia. Autonomia e Desigualdades de Gênero: contribuições do feminismo para a crítica democrática
}

\author{
Izis Morais Lopes dos Reis
}

\section{REFERÊNCIA}

BIROLI, Flávia. Autonomia e Desigualdades de Gênero: contribuições do feminismo para a crítica democrática. Vinhedo: Editora Horizonte. 208pp

1 Nas instituições sociais contemporâneas, a autonomia e a responsabilidade individual ainda se colocam com força e com frequência. Especialmente nos espaços em que as escolhas e as decisões aparecem como primordiais, há valorização da capacidade de pessoas de se engajarem nessas seleções e serem responsabilizadas por elas. É o caso, por exemplo, dos espaços constituídos como jurídicos - como os tribunais de Justiça, as prisões e o Ministério Público - e espaços pensados tradicionalmente como políticos como as casas legislativas e os cargos eletivos do Poder Executivo. Em geral, a ênfase nas liberdades de ação e de escolha, e nas condições em que esse livre-arbítrio se produz e se mantém, tem sido central para a autodefinição de sociedades que se entendem e se firmam como democráticas.

o livro de Flávia Biroli tem como objetivo contribuir com a discussão de entrecruzamentos conceituais: como gênero, classe social e raça se cruzam com a de liberdade. Ela busca avançar na crítica aos impactos (desiguais) que as ideias de plena autonomia e de escolha podem ter na vida de homens e mulheres que vivem em ambientes democráticos. A partir da análise comparativa entre variadas teorias de justiça, a autora estabelece os quadros (Goffman, 1986) que dão sentido às preferências e à autonomia no mundo da política, especificamente, e no mundo social, de forma mais 
ampla. Para isso, usa autores clássicos, como John Rawls e Ronald Dworkin, mas o aspecto central da argumentação da autora é trazer teóricas feministas. Biroli mostra, por meio de aproximações e contrastes, elucidações feministas sobre como essas organizações sociais, na democracia, conjugam valores que estão em contradição e em conflito. Autonomia, igualdade formal, justiça, desigualdades de classe social, de raça e de gênero figuram como ideais que devem ser observados com cautela.

3 Para discutir quais são os mecanismos que reproduzem assimetrias entre os gêneros e como estas causam prejuízos diferentemente à autodeterminação de mulheres e homens, a autora dividiu o livro em cinco capítulos. Eles podem ser lidos independentemente, entretanto, a leitura conjunta tem efeito iluminador e mostra a quem lê a sofisticação dos argumentos encadeados. A acumulação teórica continuada permite ao leitor, sem incursão prévia nos estudos feministas e de gênero, uma perspectiva do que significa falar em política e feminismos. Com cuidado para apresentar autoras que dialogam e que se opõem em temas variados (contrato sexual, prostituição, cuidado), a autora indica a fecundidade dessa(s) linha(s) de pensamento para demonstrar como as sociedades ditas democráticas se pensam.

4 A moldura que guia o leitor parece se apresentar nessas questões gerais que preocupam a autora: a escolha racional, base para as teorias liberais e para o libertarismo, não parece se sustentar quando o foco é deslocado de um individualismo abstrato para a posição concreta dos sujeitos, em relações sociais específicas. As teorias liberais de justiça trabalham com a centralidade das formas de vida escolhidas pelos indivíduos, desde que "as normas e as instituições garantam a igual capacidade deles para definir e buscar sua concepção de bem" (:26). Para a autora, o problema, do liberalismo, em sua versão igualitarista, seria garantir o igual respeito à autonomia dos indivíduos e corrigir condições de vida que impediriam tal liberdade - garantia de igualdade de oportunidades.

5 Biroli lança mão da crítica feminista à dualidade entre esferas pública e privada, expondo as divisões que organizam as relações entre os gêneros. Com essa armaargumento, passa a discutir como as hierarquias organizam a produção de preferências. Surge, ao longo dos próximos capítulos, um debate primário com as Ciências Sociais: o laço entre regras e ação individual - que, potencializado, pode representar uma oposição entre sociedade e indivíduo. Essa complicada relação faz com que a autora coloque em cena o conceito de "agência diferenciadamente imperfeita" (:48).

6 Postula-se que a ação individual sempre se dá em meio aos constrangimentos e às pressões, pautando o reconhecimento da impossibilidade da liberdade absoluta ou descontextualizada. As perguntas emergentes são: como mulheres podem ser parte ativa da reprodução daquilo que as oprime, como fazem escolhas que as tiranizam (e por que, então, essas não seriam seleções legítimas)? Logo, há de ser perguntado: somos livres em relações marcadas pela opressão? Autoras feministas, como Catharine Mackinnon e Iris Young são postas em diálogo para esclarecer a composição que (des)articula posturas localizadas, trajetórias individuais e coletivas e relevância teórico-política de não ver como autônomas as decisões que levam à opressão.

7 Este é outro bom debate ao longo do livro: como as opressões se entrelaçam com as subjetividades. A autora explora como as identidades criam arranjos desafiadores quando há apelo para considerar legítimas as motivações dos indivíduos. Se há adesão simples de que as percepções individuais são frutos da opressão, corre-se o risco de se desconsiderar a experiência desses indivíduos. Apresenta-se um (aparente?) paradoxo, 
em que se coloca a gramática da dominação e, simultaneamente, há ênfase nas experiências pessoalizadas, posicionadas, singulares que representariam o passo para desordenar as relações de poder estabilizadas.

8 A autora toca em mais uma tensão permanente nas análises antropológicas: como se pode entender o contínuo/conflito entre estruturas e vivências subjetivas, ou entre idioma (Evans-Pritchard, 2005) e a criatividade dos sujeitos. A difícil união entre liberdade, consentimento e opressão cria uma ficção de que os indivíduos se definiriam a despeito dos contextos e de que as preferências decorreriam dos cálculos mentais. Mas a posição feminista pauta que as escolhas se dão como desdobramentos de relaçães de poder em que mulheres estão mais vulneráveis. Para as autoras com as quais Biroli dialoga, a centralidade do trabalho doméstico na vida de mulheres se configura como fundamento para a vulnerabilidade delas.

Se, para as teorias de justiça, a liberdade de escolha e a autonomia são fundamentais para a democracia, é preciso dizer que coerção, coação, autoridade e não violência possuem fronteiras nebulosas. Isto porque nem sempre a dominação é expressa na violência. Por vezes, os constrangimentos se revelam pelos contratos que pressupõem a perda de autonomia (Carole Pateman é especificamente acionada para esta discussão). Ressalta-se que os contratos não são necessariamente escritos e assinados, mas fazem parte do repertório de negociações simbólicas entre as regras do jogo e a não violência. A alienação parcial de si faz parte do arranjo institucional desses grupos que se autoproclamam democráticos.

O último ponto trabalhado pela autora é a estreita conexão entre as teorias liberais de justiça e as ideias de família, seja como a) perspectiva de que a justiça é intergeracional; b) família pode ser um obstáculo para a justiça; c) família é locus de ensinamento moral. Entretanto, como aponta Biroli, a familia acionada é hetero-centrada e monogâmica. Diversas concepções de justiça igualitarista, mas especialmente as apresentadas por John Rawls, que levam em consideração essa instituição, falam sobre figuras de bom esposo e boa esposa - e as negociações para que essas noções de bem se constituam.

11 O esforço político de adentrar a esfera privada e de impor princípios é valorizado no texto. A crítica de Biroli se dirige às abordagens liberais por não terem se mostrado capazes de superar o problema de que as formas de preservação da intimidade - dos afetos e das escolhas como privadas - reforçam desigualdades para mulheres. Apontase a importância da crítica radical à divisão sexual do trabalho atrelada à lógica econômica com a qual as relações sociais têm cada vez mais se pensado (com a redução do tempo livre e o aumento da carga de trabalho remunerado e não remunerado). Esta divisão baliza o empobrecimento de mulheres, relegadas ao cuidado de pessoas com dependências diversas - prática socialmente desvalorizada.

o olhar das autoras feministas é apresentado para deslocar o holofote das responsabilidades individuais sobre os membros de uma família - e as escolhas privadas que as formariam - para as relações socialmente estruturadas. O vigor do par autonomia/responsabilidade desconsidera que o cuidado e a dependência são partes constituintes das relações humanas, e não um desvio da normalidade. Logo, em uma divisão do trabalho em que o doméstico e o próprio cuidado são relegados à ilegitimidade (ou à ideia de que não se está fazendo nada porque não há produção econômica direta), a tarefa de cuidar será sempre produtora de desigualdades (independentemente de quem realize esse trabalho). 

para pensar a autonomia no contexto de justiça (ou de projetos de justiça). E, embora a autora argumente com precisão sobre a necessidade de se levarem contextos e experiências singulares quando as preferências são expressadas em sociedades democráticas, há silêncio sobre o que democracia pode significar. Conceitos como indivíduo e sociedade passam pelo escrutínio teórico para tentar superar dualismos [como indicariam Roy Wagner (2010) e Marilyn Strathern (2006)]. Porém, a mesma postura não aparece quando democracia, sociedades e Estados democráticos são citados.

A reflexividade sobre esse(s) conceito(s) pode ser ferramenta útil para avançar na compreensão sobre como autonomia e instituições sociais se vinculam, como autodeterminação e justiça se enlaçam. Isto porque democracia e participação social podem adquirir diferentes significados a depender da posição social de quem as maneja (autores/as, atores políticos, feministas). o que está colocado é uma arena de negociações sobre como deve ser o mundo, o político como terreno da celebração dos valores centrais para uma sociedade. Concordo com Michael Herzfeld (1993) quando chama a atenção para a qualidade semântica presente nas burocracias estatais. Todos os símbolos são passíveis de comportar múltiplos significados, tanto os gerados no dia a dia das práticas burocráticas como aqueles que já parecem ter estabilidade e legitimidade suficiente para mobilizar afetos e militâncias políticas (como parece ser o caso da democracia).

O livro é ótimo para profissionais de instituições comprometidos com os processos de modificação de teorias e práticas de intervenção social, assim como serve como ponto de partida para operadores do direito que atuam com garantias e disputas por direitos especialmente após a Lei Maria da Penha. Sugere-se o livro também para estudantes de graduação e pós-graduação que pretendem compreender a articulação entre feminismos, teorias de gênero e articulações políticas.

\section{BIBLIOGRAFIA}

EVANS-PRITCHARD, Edward E. 2005. Bruxaria, oráculos e magia entre os Azande. Rio de Janeiro: Zahar. (Versão condensada por Eva Gillies, traduzida por Eduardo Viveiros de Castro).

GOFFMAN, Erving. 1986. Frame analysis. Nova York: Harper \& Row.

HERZFELD, Michael. 1993. The Social Production of Indifference: exploring the symbolic roots of western bureaucracy. London: University of Chicago Press.

STRATHERN, Marilyn. 2006. O Gênero da Dádiva: problemas com as mulheres e problemas com a sociedade na Melanésia. Campinas: Editora Unicamp.

WAGNER, Roy. 2010. A invenção da cultura. São Paulo: Cosac Naify. 
AUTORES

IZIS MORAIS LOPES DOS REIS

PPGAS/UnB 